\title{
Effectiveness of evidence based regimen for medical abortion over conventional methods
}

\author{
Anitha K. Gopal*, Sajini B., Ganamurali S., Beena Kumari R.
}

Department of Obstetrics and Gynecology, Government Medical College Kottayam, Kerala, India

Received: 25 January 2017

Revised: 09 February 2017

Accepted: 09 February 2017

\section{*Correspondence:}

Dr. Anitha K. Gopal,

E-mail: dranithakgopal@gmail.com

Copyright: ( $)$ the author(s), publisher and licensee Medip Academy. This is an open-access article distributed under the terms of the Creative Commons Attribution Non-Commercial License, which permits unrestricted non-commercial use, distribution, and reproduction in any medium, provided the original work is properly cited.

\begin{abstract}
Background: Medical abortion is a means of medical termination of pregnancy by drugs alone. This can be done upto 63 days using mifepristone and misoprostol tablets. For the conventional method, patient has to come to the hospital 3 times. In our study we reduced the interval between the drugs there by reducing the number of hospital visits. The objectives were to study the reduction of induction abortion interval following administration of evidence based regimen and to compare the proportion of patients developing complications in both the groups.

Methods: It was a comparative study conducted at Department of Obstetrics and Gynecology, Govermnent Medical College Kottayam, Kerala, India from May 2015 to November 2015.

Results: The mean induction abortion interval in experimental group was 14.3 hours and in control group, it was 60.4 hours which was found to be statistically significant. Only 3 patients (7\%) of experimental group had side effects whereas 12 patients. (17.4\%) had side effects in the control group. Major side effects encountered were severe abdominal pain and severe bleeding per vaginum. Evidence based regimen consist of administration of mifepristone $200 \mathrm{mg}$ and vaginal misoprostol $600 \mu \mathrm{g} 6$ hours later for termination of pregnancy up to 63 days could reduce the induction abortion interval by 46 hours and had less side effects.

Conclusions: As it reduces the induction abortion Interval and complications we feel that the evidence based regimen for Medical Termination of Pregnancy is superior to the FDA approved regimen.
\end{abstract}

Keywords: Mifepristone, Misoprostol, Pregnancy, Unwanted

\section{INTRODUCTION}

Medical termination of pregnancy is defined as the wilful termination of unwanted pregnancy before viability i.e. before 20 weeks of pregnancy. ${ }^{1}$ In India more than six million abortions occur every year. Of these 4 million cases are induced abortion but very few of these are reported and the remaining are done illegally. ${ }^{2}$ This is associated with increased morbidity and mortality from severe anaemia and sepsis.

With the availability of prostaglandins in the early 1970s followed by the development of antiprogesterone in 1980s, Medical abortion became an alternative method of
MTP. Medical method of MTP is preferred to surgical method because complications like uterine perforation, uterine adhesions, fainting/syncope associated with forceful cervical dilatation are less with medical methods.

Termination of pregnancy with mifepristone and misoprostol has been established as a safe method for terminating early pregnancy up to 9 weeks (63 days) from the first day of last menstrual period.

\section{Conventional medical methods}

Mifepristone $200 \mathrm{mg}$ is given followed by $400 \mu \mathrm{g}$ misoprostol orally/ vaginally after 48 hours. 
$1^{\text {st }}$ visit (Day 1)

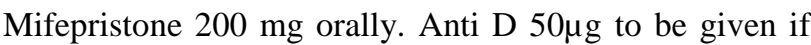
the women in $\mathrm{Rh}-\mathrm{ve}$. Patient is asked to come on the $3^{\text {rd }}$ day.

$2^{\text {nd }}$ visit (Day 3)

Oral/vaginal misoprostol $400 \mu \mathrm{g}$ is given. Patient is counselled for follow up after 14 days and earlier if there is prolonged bleeding, fever of foul smelling discharge $\mathrm{PV}$.

$3^{r d}$ Visit (Day 15)

A detailed history is taken regarding fever, severe abdominal pain or foul smelling discharge PV. General examination is done to see whether there is fever or aneamia. Pelvic examination is done to ensure complete abortion and to rule out complications like incomplete expulsion or sepsis. Ultra sound scan is performed to ensure complete expulsion of products of conception.

All together the patient has to come for 3 times for the termination of pregnancy.

\section{Evidence based regimen}

$200 \mathrm{mg}$ of oral mifepristone is given. This is followed by $600 \mu \mathrm{g}$ of misoprostol vaginally after $6 \mathrm{hrs}$.

Based on efficacy and adverse effects evidence based protocols for medical abortion are superior to the FDA approved regimen. Regimens that use vaginal misoprostol can be given simultaneous with mifepristone to terminate gestations up to 63 days. ${ }^{4}$ A $6-8$ hours interval between mifepristone administration and vaginal misoprostol is as effective as a 48 hours interval and result in fewer side effects.

In our institution, most of the patients for MTP are coming from distant places, more than $100 \mathrm{~km}$ from our area. When we use the conventional method, it is common that patient does not come for follow up and later attend the casualty with complications such as severe anaemia, sepsis. If we can reduce the Induction Abortion Interval, we can reduce the number of hospital visits and thereby reduce the complication rate and the economic burden of the patient and their relatives.

\section{Aims and objectives}

- To study the reduction in Induction Abortion Interval following the administration of evidence based regimen.

- To compare the proportion of patients developing complications in both case and control groups.

\section{METHODS}

\section{Study design}

It is a comparative study.

\section{Study setting}

Family planning unit, Department of obstetrics and Gynecology, Government Medical College, Kottayam, Kerala, India.

\section{Period of study}

May 2015 to November 2015

\section{Inclusion criteria}

Uncomplicated patients coming for MTP up to 63days, under MTP act. Those willing for surgical intervention in case of incomplete expulsion.

\section{Exclusion criteria}

- Those more than 63 days of gestation

- Twins and Previous Caesarean Section cases

- Complications like anemia, fever, liver or kidney diseases, angina, Coagulopathy, valvular heart diseases

- Patients with purulent vaginal discharge/ candidiasis

\section{Sample size}

Calculated by using statistical software, $\mathrm{n}$ Master with inputs from review of literature.

Sample size

$$
\begin{aligned}
& \mathrm{n}=\frac{2 \mathrm{Sp}^{2}\left(\mathrm{Z}_{1}-\mathrm{a} / 2+\mathrm{Z}_{1}-\beta\right)^{2}}{\mu \mathrm{d}^{2}} \\
& \mathrm{Sp}^{2}=\frac{\mathrm{S} 1^{2}+\mathrm{S} 2^{2}}{2}
\end{aligned}
$$

From literature

$\mathrm{S}_{1}=3.1$ (Standard deviation of time of onset of bleeding in the study group)

$\mathrm{S}_{2}=2.5$ (Standard deviation of time of onset of bleeding in the control group)

$\mu \mathrm{d}^{2}=1.7$ (Mean difference in time of onset of bleeding in two groups.)

$$
\mathrm{n}=\frac{2 \times 2.8^{2}(7.849)}{1.7^{2}}
$$

$=43$ per group 


\section{Ethical committee certificate}

Government Medical College

Kottayam, Kerala 686008, India

Institutional Review Board

Communication of Decision of the Institutional Review Board (IRB)

IRB No: 42/2015

\section{Procedure}

Women were diagnosed as pregnant with urine pregnancy test. Intra uterine pregnancy was confirmed by the ultra sound scanning and gestational age was confirmed up to 63 days. Detailed history and complete clinical examination were done to exclude any complications. After the women were found suitable for medical method of pregnancy termination, they were counseled on the relevant aspects related to the procedure and after getting the written consent, the clinical protocol given below was followed.

The patients were numbered. The odd numbers were considered as cases and even numbers as controls. Findings were confirmed by P/S (per speculum) and P/V (per vaginal) examination.

For all Cases, $200 \mathrm{mg}$ Mifepristone was administrated orally and after 6 hours, $600 \mu \mathrm{g}$ of Misoprostol was administrated vaginally. They were kept under observation for 6 hours.

For the controls, $200 \mathrm{mg}$ mifepristone was administered orally and they were advised to come on the third day for vaginal administration of $400 \mu \mathrm{g}$ misoprostol. The controls too were then kept under observation for 6 hours. If $\mathrm{Rh}$-ve women were present among the patients, AntiD was administered to them. Both cases and control groups were then asked to record the following for the next 14 days.

- The onset of bleeding

- Timing of passage of product of conception

- Duration of bleeding and

- Any possible side effects

They were then instructed to report to hospital on the 15 th, or on any other day in between, in case of heavy bleeding (soaking of $>2$ pads/hour for more than 2 hours)

On the $15^{\text {th }}$ day, USS and clinical examination was performed to determine the result. Failure of medical abortion was defined when a surgical curettage was performed for any reason. If cardiac activity was present, it was considered as a true failure of the drug.

\section{Tools}

- A structured proforma was used to record information
- USS scan reports

- UPT

- Blood investigation reports

- $\quad$ Statistical methods

To compare the homogeneity of the group chi square test was used when the level of measurement is nominal. To compare interval/ratio level measurements $t$ test was used. Measures of central tendency and dispersion were used whenever necessary. Significance level was fixed at $5 \%(0.05)$.

All the analysis was done using SPSS version 20.

\section{RESULTS}

86 patients were included in the study. 43 in the case group using evidence based regimens and 43 in the control group using conventional method of MTP.

Table 1: Age.

\begin{tabular}{|lll|}
\hline Age & $\begin{array}{l}\text { Experimental } \\
\text { group }\end{array}$ & $\begin{array}{l}\text { Control } \\
\text { group }\end{array}$ \\
\hline Mean & 31.47 & 30.86 \\
\hline Standard deviation & 5.2 & 5.7 \\
\hline Minimum & 21 & 18 \\
\hline Maximum & 40 & 41 \\
\hline
\end{tabular}

Mean age in case group was 31.47 years and control group was 30.86 . The minimum age in case group was 21 years and control group was 18. Maximum age is case group was 40 and that of control group was 41 .

Table 2: Parity.

\begin{tabular}{|lllllll|}
\multirow{2}{*}{ Gravida } & \multicolumn{2}{l}{ Experimental } & \multicolumn{2}{l}{ Control } & Total \\
\cline { 2 - 7 } & No. & $\%$ & No. & $\%$ & No. & $\%$ \\
\hline 1 & 1 & 2.3 & 4 & 9.3 & 5 & 5.8 \\
\hline 2 & 15 & 34.9 & 16 & 37.2 & 31 & 36 \\
\hline 3 & 19 & 44.2 & 18 & 41.9 & 37 & 43 \\
\hline 4 & 4 & 9.3 & 4 & 9.3 & 8 & 9.3 \\
\hline 5 & 4 & 9.3 & 1 & 2.3 & 5 & 5.8 \\
\hline Total & 43 & 100 & 43 & 100 & 86 & 100 \\
\hline
\end{tabular}

High proportion of both groups belonged to gravida 2 and 3 which constituted $79.1 \%$ in case as well as control group.

The mean gestational age in case group was 51.95 days and in control group was 51.98 days. In case group minimum gestational age was 35 and in control group 31 days. Maximum gestational age in case and control group was 63 days.

In the case group mean time of onset of bleeding was 9.1 hours and in control group it was $53.2 \mathrm{hrs}$. Minimum time 
of onset of bleeding in Case group was 7 hours and in control group it was 49 hours.

Table 3: Gestational age.

\begin{tabular}{|lll|}
\hline Gestational age & Experimental & Control \\
\hline Mean & 51.95 & 51.98 \\
\hline Standard deviation & 9.131 & 7.466 \\
\hline Minimum & 35 & 37 \\
\hline Maximum & 63 & 63 \\
\hline
\end{tabular}

Table 4: Comparison of time of onset of bleeding.

\begin{tabular}{|lllll|} 
Group & Mean & SD & t value & p value \\
\cline { 1 - 4 } Experimental & 9.1 & 0.9 & 142.3 & \multirow{2}{*}{$<0.001$} \\
\cline { 1 - 3 } Control & 53.2 & 2 & & \\
\hline
\end{tabular}

Table 5: Comparison of induction abortion interval.

\begin{tabular}{|lllll|}
\hline Group & Mean & SD & t value & p value \\
\cline { 1 - 4 } Experimental & 14.3 & 2.8 & 72.1 & \multirow{2}{*}{$<0.001$} \\
\hline Control & 60.4 & 3.1 & & \\
\hline
\end{tabular}

The mean induction abortion interval in case group was 14.3 hours compared to 60.4 hours in control group, which was statistically significant $(\mathrm{P}<0.001)$. Minimum induction abortion interval in Case group was 2 hours and maximum was 20 hours. For the control group, minimum was 20 hours and maximum was 64.5 hours.

Table 6: Side effects.

\begin{tabular}{|l|llllll|}
\hline \multirow{2}{*}{$\begin{array}{l}\text { Side } \\
\text { effects }\end{array}$} & \multicolumn{2}{l}{ ERPerimental } & \multicolumn{3}{l}{ Control } & \multicolumn{2}{l|}{ Total } \\
\hline No. & $\%$ & No. & $\%$ & No. & $\%$ \\
\hline Absent & 40 & 93 & 31 & 72.1 & 71 & 82.6 \\
\hline Present & 3 & 7 & 12 & 27.9 & 15 & 17.4 \\
\hline Total & 43 & 100.0 & 43 & 100.0 & 86 & 100 \\
\hline
\end{tabular}

$\chi^{2}=6.5, p=0.011$. Side effects were significantly lower in the experimental group.

\section{DISCUSSION}

Medical abortion has been a revolution in obstetric practice. The procedure is well known for its safety and easiness to perform. Over the past 5 years multiple studies have focused on the time interval between the two medications. ${ }^{5,6}$ Decreasing the time interval allows most women to complete the process in lesser time and with lesser adverse effects. Various studies have shown that peak serum concentration of mifepristone is more or less equal for a dose that ranges between $100 \mathrm{mg}$ and $800 \mathrm{mg} .{ }^{7,8}$ On the basis of this fact $200 \mathrm{mg}$ single dose of mifepristone was used in the study. Various studies reported $95 \%$ success rate with vaginal misoprostol compared to the $87 \%$ success rate of oral misoprostol at 48 hour interval., ${ }^{9,10}$ This was because systemic bioavailability of misoprostol was 4 times higher through vaginal route when compared with oral route and peak level was attained more slowly but was sustained for longer periods. ${ }^{11}$

The success rate of taking a 48 hour interval between the medications ranges from $92-97 \% .^{2,12}$ Crenin et al reported success rate of 24 hour regimen to be $98.1 \%$ and $96.9 \%$ in their studies carried out in 2004 and 2007. ${ }^{19}$

In present study the success rate is $100 \%$. So also in our study, the occurrence of side effects was found to be less, compared to the control group. In the present study satisfaction rate was not analysed but generally most of the women were satisfied with the therapy they received.

The FDA approved regimen can be initiated up to 49 days and consists of mifepristone $600 \mathrm{mg}$ orally on day 1 , Misoprostol $400 \mu \mathrm{g}$ orally on day 3 and follow up on days 12-20. This protocol is $92 \%$ effective in inducing a complete abortion. ${ }^{14,15}$ It has been shown by the WHO and others that a lower dose of mifepristone is just as effective as the $600 \mathrm{mg}$ dose. ${ }^{16,17}$ This is especially important for reducing the cost of medical abortion. A total of $95 \%$ of women who inserted $800 \mu \mathrm{g}$ misoprostol vaginally after taking $600 \mathrm{mg}$ mifepristone up to 63 days of post LMP had complete abortion as compared with $87 \%$ of women who took the lower oral dose of misoprostol. ${ }^{18}$ This study and others confirmed that vaginal administration of misoprostol is superior to oral administration and that for women initiating medical termination of pregnancy between 49 and 63 days, only vaginal misoprostol application is recommended. The incidence of gastrointestinal side effects from misoprostol seems to be lower with vaginal administration.

Over the past 5 years multiple studies have focused on the time interval between the two medications. ${ }^{19,20}$ Decreasing the time interval allows most women to complete the process in lesser time. The success rate of 48 hour interval ranges from 92-97\%.2,12 Crenin et al reported success rate of 24 hour regimens to be $98.1 \%$ and $96.9 \%$ Coege et al showed a higher percentage of women in $48 \mathrm{hr}$. interval group reported side effects such as nausea and vomiting after mifepristone and administration than women in $24 \mathrm{hr}$. group.,21

All these studies show that vaginal administration of misoprostol after priming with $200 \mathrm{mg}$ of mifepristone will induce abortion with less gastrointestinal side effects. By reducing the time of administration of misoprostol we can reduce the time of onset of bleeding.

Medical abortion approved by FDA is $200 \mathrm{mg}$ mifepristone $+600 \mu \mathrm{g}$ misoprostol after 48 hours. As per this regime the patient has to come for three days to the hospital for completion of the process. The present study shows the efficacy of mifepristone $200 \mathrm{mg}$ and misoprostol $600 \mu \mathrm{g}$ vaginally after 6 hours. Thus we can reduce the induction abortion interval time and thereby the number of hospital visits. The present study was planned to find a safe, simple and optimally effective 
regimen of mifepristone and misoprostol for abortion of pregnancy within 63 days.

Srivasthava in 2006 performed a similar research in nepal medical college and assessed the safety and efficacy. In her prospective study misoprostol was used vaginally and the success rate was $92.6 \% .^{11}$ Kathleen et al in 2011 performed a similar research with Misoprostol administered vaginally and the success rate was $80 \% .^{22}$

\section{Evidence based regimen}

Evidence based regimens have been developed to improve medical abortion in terms of expense, safety, speed and adverse effect. The regimen that use low doses of mifepristone $(200 \mathrm{mg})$ have similar efficiency and lower cost compared with those that use mifepristone $600 \mathrm{mg}$. Based on efficiency and adverse effects profile, evidence based protocol for medical abortion are superior to FDA approved regimens. By changing route of misoprostol administration, the timing between mifepristone and misoprostol dosing can be varied. There are regimens that use vaginal misoprostol simultaneously with mifepristone to terminate gestations up to 63 days. ${ }^{4}$ A 6-8 hours interval between mifepristone administration and vaginal misoprostol is as effective as a 48 hour interval and result in fewer side effects. ${ }^{5}$

\section{CONCLUSION}

From the present study it was concluded as it reduces the induction abortion Interval and complications we feel that the evidence based regimen for Medical Termination of Pregnancy is superior to the FDA approved regimen.

\section{ACKNOWLEDGEMENTS}

Authors are extremely thankful to Dr. T. J. Cicily, Professor, Head of the Department of Obsterics and Gynecology for the valuable suggestions and guidance. Authors thank the members of Family Planning Unit for their whole hearted support for this study. Authors also express our sincere thanks to all the patients who participated in present study. Above all, authors are grateful to Almighty God for his blessings that have led to the completion of this study.

Funding: No funding sources Conflict of interest: None declared

Ethical approval: The study was approved by the Institutional Ethics Committee. IRB No: 42/2015

\section{REFERENCES}

1. Sathyavathi K, Kamala Ganesh. Medical Termination of Pregnancy. IGNOU; 2008:91-104.

2. Verma M, Singh U, Singh N, Shankhwar P, Srivasthava D. Efficacy of misoprostol administration 24 hours after mifepristone for termination of early pregnancy. Indian J Med Sci. 2011;65(12):511-7.

3. Ministry of health and family welfare, GOI. Comprehensive abortion care 2010. Chapter 6, page 39-48.

4. Crenin MD, Grossman D. Medical management of first trimester abortion. ACOG Pract Bull. 2014;143:1-17.

5. Crenin MD, Fox MC, Teal S, Chen A, Schaff EA, Meyn LA. Randomised comparison of misoprostol 6-8 hrs versus $24 \mathrm{hrs}$ after mifepristone for abortion. MOD study trial group. Obstet Gynecol. 2004;103(5 Pt 1):851-9.

6. Shi YE, Ye ZH, He CH, Zhang GQ, Xu JQ, Van Look PF, et al. Pharmacokinetic study of RU 486 and its metabolites after oral administration of single doses to pregnant and non-pregnant women. Contraception. 1993;48:133-49.

7. Swahn ML, Wang G, Aedo AR, Cekan SZ, Bygdeman M. Plasma levels of antiprogestin RU 486 following oral administration to non-pregnant and early pregnant women. Contraception. 1986;34:46981.

8. Guest J, Chien PF, Thomson MA, Kosseim ML. Randomised controlled trial comparing the efficacy of same-day administration of mifepristone and misoprostol for termination of pregnancy with the standard 36 to 48 hour protocol. BJOG. 2007;114:207-15.

9. El-Refaey H, Rajasekar D, Abdalla M, Calder L, Templeton A. Induction of abortion with mifepristone and oral or vaginal misoprostol. N Engl J Med. 1995;332:983-7.

10. Tang OS, Gemzell-Danielsson K, Ho PC. Misoprostol: Pharmacokinetic profiles, effects on the uterus and side-effects. Int $\mathrm{J}$ Gynaecol Obstet. 2007;99:S160-7.

11. Shrivastava V. Safety efficacy and acceptability of medical abortion with mifepristone and misoprostol in Nepalese women. Nepal $\mathbf{J}$ Obstet Gynecol. 2007;2(2):54-8.

12. Coyaji K, Krishna U, Ambardekar S, Bracken H, Raote V, MAndlekar A et al. Are two doses of misoprostol after mifepristone for early abortion better than one? BJOG. 2007;114:271-8.

13. Urquhart DR, Templeton AA, Shinewi F, Chapman M, Hawkins K, McGarry J. The efficacy and tolerance of mifepristone and prostaglandin in termination of pregnancy of less than 63 days gestation: UK Multicentre Study- final results. Contraception. 1997;55:1-5.

14. Petron R, Auveny E, Targosz V. Early termination of pregnancy with mifepristone (RU486) and the orally active prostaglandin misoprostol. N Engl J Med. 1993; 328:1509-13.

15. Spitz IM, Barbin CW, Benton L, Robbins A. Early pregnancy termination with mifepristone and misoprostol in the United States. N Engl J Med. 1998;338:1241-7. 
16. World Health Task Force on post ovulatory methods of fertility regulation. Comparison of two doses of mifepristone in combination with misoprostol. 2000;107:524-30.

17. Ashok PW, Pnney GC, Flet GM, Templeton A. An effective regimen for early medical abortion: A report of 2000 consecutive cases. Hum Reprod. 1998;13:2962-5.

18. Royal College of Obstetricians and Gynecologist. The care of women requesting induced abortion. London: RCOG press; 2004.

19. Crenin, Schwartz, Pymar, Fink. Efficacy of mifepristone followed on the same day by misoprostol for early termination of pregnancy; report of a randomized trial. BJOG. 2001; 108(5):469-73.

20. Schaffea, Fielding SL, Westhoff C, Ellertson C, Eisinger SH, Stadalius LS et al. Vaginal misoprostol administered one two or three days after mifepritone for early medical abortion: A Randomised trial. JAMA. 2000;284:1948-53.

21. Crenin MD, Schreiber CA, Bednarek P, Lintu H, Wagner MS, Meyn LA, et al. Mifepristone and misoprostol administered simultaneously versus 24 hrs apart for abortion :A randomized control trial. Obstet Gynecol. 2007;109:885-94.

22. Kathaleen K, Lesli M, Patrisia L, Mithcell D. Mifepristone and misoprostol for early pregnancy failure. Am J Obstet Gynecol. 2011;204(5):386.

Cite this article as: Gopal AK, Sajini B, Ganamurali S, Kumari BR. Effectiveness of evidence based regimen for medical abortion over conventional methods. Int J Reprod Contracept Obstet Gynecol 2017;6:881-6. 